\title{
O ensino dos conceitos de solstício e equinócio e das estações do ano a partir do uso de gif como recurso didático
}

the teaching of the concepts of solstice and equinox and of the seasons of the year from the use of gif as a didactic resource

La enseñanza de los conceptos de solstício y equinocio y de las estaciones del año a partir del uso de gif como recurso didáctico

Hélen Maria Mendes de Sene Licenciada em Ciências Biológicas, UFLA, Brasil. helen_pgh@hotmail.com

André Luiz Silva Andrade Licenciado em Ciências Biológicas, UFLA, Brasil. andreluiz.gti@gmail.com

André Maciel da Silva Licenciado em Ciências Biológicas, UFLA, Brasil. andremacial_29@hotmai.com

Jose Alberto Casto Nogales Vera Professor Doutor, UFLA, Brasil. jnogales@dfi.ufla.br

Antonio Fernandes Nascimento Junior

Professor Doutor, UFLA, Brasil. toni_nascimento@yahoo.com.br 


\section{RESUMO}

A preocupação com a formação inicial de professores vem sendo crescente nos últimos tempos, podendo ser observada pela criação dos Programas Institucionais de Bolsa de Iniciação à Docência (PIBIDs). Com isso, e o rápido avanço da mídia na atualidade, é importante considerarmos a inserção dela no ambiente escolar, utilizando essa grande ferramenta presente no dia a dia dos alunos a favor da educação. Uma maneira de responder a essa realidade é incorporar a mídia na formação inicial de professores, permitindo um contato mais aprofundado entre ambos, para que eles se tornem confiantes e aptos a utilizar a mídia como um recurso pedagógico. Já nas instituições escolares, há uma grande dificuldade pela maioria dos alunos em enxergar a ciência inserida no seu cotidiano, sendo assim, o uso da mídia como recurso pedagógico demonstra ter um grande potencial para sanar esse obstáculo enfrentado dentro da sala de aula, tornando possível aproximar o aluno do conteúdo científico. A partir dessa observação, foi desenvolvido um recurso didático durante a disciplina de Metodologia do Ensino de Ciências do curso de licenciatura em Ciências Biológicas da Universidade Federal de Lavras (UFLA), com objetivo de construir uma estratégia pedagógica que contemple essa dimensão. Ainda no âmbito da disciplina, a estratégia foi apresentada e realizada com os alunos participantes da disciplina e também do (PIBID) de biologia, que a avaliaram. As falas dos participantes foram analisadas com base na literatura e trouxeram algumas questões como o desempenho dos licenciandos e a clareza de entendimento proporcionada pelos GIFs.

PALAVRAS-CHAVE: Formação Professores. GIFs. Ensino de Ciências. Mídia.

\section{ABSTRACT}

The concern about the initial training of teachers has been increasing in recent times, and can be observed by the creation of PIBIDs. With this and the rapid advance of the media nowadays, it is important to consider its insertion in the school environment, using this great tool present in the students' daily life in favor of education. A way to answer this reality is to incorporate the media into the initial teacher training, allowing a more in-depth contact between both, so that they become confident and able to use the media as a pedagogical resource. In school institutions, there is a great difficulty for most students to see the science inserted in their daily life, and thus, the use of the media as a pedagogical resource demonstrates a great potential to remedy this obstacle faced within the classroom, making it possible to bring the student closer to the scientific content. From this observation, a teaching resource was developed during the Science Teaching Methodology subject of the licentiate course in Biological Sciences of the Federal University of Lavras (UFLA), aiming to construct a pedagogical strategy that contemplates this dimension. Still within this scope, the strategy was presented and carried out with the students participating in the course and in PIBID, who evaluated it. The participants' speeches were analyzed based on the literature and brought some questions such as the graduate's performance and the clarity of understanding provided by GIFs.

KEYWORDS: Teacher Formation. GIFs. Science Teaching. Media.

\section{RESUMEN}

La preocupación por la formación inicial de los profesores ha ido en aumento en los últimos tiempos, pudiendo ser observada por la creación de los Programas Institucionales de Beca de Iniciación a la Docencia (PIBIDs). Con eso, y el rápido avance de los medios en la actualidad, es importante considerar la inserción de ella en el ambiente escolar, utilizando esa gran herramienta presente en el día a día de los alumnos a favor de la educación. Una manera de responder a esta realidad es incorporar a los medios en la formación inicial de profesores, permitiendo un contacto más profundo entre ambos, para que ellos se vuelvan confiados y aptos para utilizar los medios como un recurso pedagógico. En las instituciones escolares, hay una gran dificultad por la mayoría de los alumnos en ver la ciencia insertada en su cotidiano, siendo así, el uso de los medios como recurso pedagógico demuestra tener un gran potencial para sanar ese obstáculo enfrentado dentro del aula, haciendo posible Aproximar al alumno del contenido científico. A partir de esa observación, se desarrolló un recurso didáctico durante la disciplina de Metodología de la Enseñanza de Ciencias del curso de licenciatura en Ciencias Biológicas de la Universidad Federal de Lavras (UFLA), con el objetivo de construir una estrategia pedagógica que contemple esa dimensión. En el marco de la disciplina, la estrategia fue presentada y realizada con los alumnos participantes de la disciplina y también del (PIBID) de biología, que la evaluaron. Las palabras de los participantes se analizaron sobre la base de la literatura y traían algunas cuestiones como el rendimiento de los licenciandos y la claridad de entendimiento proporcionada por los GIF.

PALABRAS CLAVE: Formación Profesores. GIFs. Enseñanza de Ciencias. Medios. 


\section{INTRODUÇÃO}

É papel dos educadores, entre outras coisas, desenvolver a criticidade nos alunos, levando-os a compreender as informações que até eles chegam. A mídia veicula diversas informações que em uma leitura superficial, não expressam interesses e desejos próprios. Porém, com uma análise mais crítica podemos perceber que ela revela diversas informações "não-ditas" que são essenciais para uma boa leitura do conteúdo veiculado. Sendo assim, a mídia é de grande importância na formação tanto de professores quanto de estudantes, já que vivemos em um mundo onde elas estão onipresentes, sendo preciso considerar sua importância na vida social, particularmente no que diz respeito aos jovens (BÉVORT e BELLONI, 2009, p.1081). Para essas autoras, se faz necessário também que a apropriação da mídia seja crítica e criativa, pois a mesma é indispensável ao exercício da cidadania. As autoras ainda destacam que essa ferramenta além de ter grande importância, é um sofisticado dispositivo técnico de comunicação que atua de várias maneiras na vida social, não somente com funções efetivas de controle social (político, ideológico...). Segundo elas, as mídias geram modelos novos de conceber a realidade, de produzir, reproduzir e propagar informações e conhecimentos.

Proporcionar situações de aprendizagem despertando o interesse pelo assunto com essas metodologias é um avanço que deve ser alcançado conjuntamente por todos os envolvidos no processo (TROVO, 2008).

Além disso, esse recurso não é apenas uma forma de socialização e transmissão simbólica, mas também uma forma de construção da compreensão do mundo, o que demonstra a importância das mediações culturais e pedagógicas nesse processo. Com isso, é necessário construir e apoiar novas formas de apropriação das práticas sociais que envolvem leitura e escrita, sobretudo as relacionadas à cultura digital (FANTIN e GIRARDELLO, 2009, p.79).

Diante disto, a mídia assume importante papel na formação de professores, pois, para se formar um aluno crítico e criativo, devemos primeiramente formar docentes que desenvolvam também estas características. Entretanto, no limiar deste século, as grandes maiorias dos profissionais da educação ainda não se veem preparados para o enfrentamento de metodologias que utilizem esses recursos tecnológicos (DORIGONI e SILVA, 2008).

Desta forma, devemos repensar práticas, currículo, ações e pesquisa, contemplando essa discussão na formação inicial e/ou continuada de professores.

\section{O GIF como um recurso didático}

O GIF (Graphics Interchange Format), de acordo com Suhr (2014), é uma série de imagens salvas como um único arquivo. Essas imagens são então exibidas em sequência, como uma história em quadrinhos onde cada quadro é mostrado separadamente dentro de um específico intervalo de tempo, formando uma espécie de animação em vídeo. Esse tipo de apresentação de imagens, diferentemente dos vídeos, possibilita que todas as etapas de um determinado processo possam ser vistas e revistas sem que o usuário precise recarregá-la ou reiniciá-la.

Foram introduzidos no ano de 1987 e logo difundiram-se por causa dos baixos requisitos de computação, pela alta portabilidade e por ser compatível com diversos navegadores 
(MIGLIOLI; BARROS, 2013). Outra vantagem dos GIFs é que a maioria deles não apresenta legendas e nem textos autoexplicativos, permitindo uma maior flexibilidade para que o professor construa o conhecimento com os alunos através de problematizações feitas a partir deles. Essa proposta vai de acordo com o pensamento de Silva et al. (2006), pois há a necessidade de que educadores preparados para procedimentos didáticos privilegiem a elaboração coletiva de conhecimentos mediados pelo uso da imagem, com a orientação dessa construção mediada pelo professor. Os GIFs ainda podem ser construídos com pequenas partes de vídeos, que ganham sentido quando inseridas conforme o desejo do criador (SUHR, 2014).

Podem ser encontrados em plataformas como o Tumblr ${ }^{1}$, bem como em sites como o Reddi ${ }^{2} \mathrm{e}$ - Buzzfeed ${ }^{3}$, além de blogs como Como Me Sinto Quando, que servem como uma cultivadora digital de documentos animados (MIGLIORI e BARROS, 2013). Há também o repositório de GIFs GIPHY que disponibiliza GIFs específicos por temas, como por exemplo o de ciência (https://giphy.com/search/science). Este recurso pode consistir em uma imagem estática como nos formatos JPEG ou PNG. Porém seu diferencial comparado a outros formatos de imagem, é o fato de o GIF também suportar animações (LUPINACCI, 2016).

Migliori (2013) afirma que os GIFs são especialmente apropriados para a atual maneira de consumo cultural, bem como para o desempenho de diversas funções que outros formatos de mídia não o fariam. No caso de imagens animadas, pelo fato de serem sequências de imagens em movimento, o procedimento acontece em menor espaço temporal, uma vez que o usuário não precisa acessar cada imagem de forma separada. Além do mais, os GIFs quebram as barreiras da limitação tecnológica, pois a extensão do arquivo é pequena.

Como afirmam Migliori e Barros (2013), os GIFs animados geralmente são produzidos a partir da utilização de um software de edição de imagem, e uma série de fotografias ou uma gravação de vídeo, que resulta em uma composição de quadros sequenciais em um loop contínuo, muitas vezes resultando em uma espécie de vídeo. Então se uma escola não tem acesso à internet de alta velocidade, as imagens animadas podem substituir os vídeos, uma vez que são menores.

No mundo em que vivemos, a indústria midiática tem se alterado significativamente e de forma bastante acelerada. A evolução tecnológica possibilitou o suprimento da demanda de uma comunicação mais colaborativa e horizontal.

A prática cultural de consumo de conteúdos midiáticos vem se modificando. Circulam hoje na web diversos conteúdos que visam agradar e suprir a demanda de um público cada vez mais exigente, que busca a maior quantidade de entretenimento num menor espaço de tempo. De acordo com Lupinacci (2014), hoje em dia qualquer pessoa pode começar a "escrever" usando texto, imagens, músicas ou vídeo, e progressivamente pessoas estão modelando, compartilhando e reconfigurando conteúdos de mídia dentro de comunidades e redes (JENKINS et al. apud Lupinacci, 2016).

\footnotetext{
${ }^{1}$ http://www.tumblr.com

${ }^{2}$ http://www.reddit.com

${ }^{3}$ http://www.buzzfeed.com
} 
Ainda segundo o autor, a comunicação baseada em imagens não é novidade. Pictogramas e ideogramas já faziam parte da base da escrita de várias culturas, desde a época do homem das cavernas, assim como no Egito Antigo (2016, p.14). Que a comunicação há muito tempo é baseada na imagem, já é sabido por todos, mas se tratando de transmissão de imagens nos dias de hoje, os GIFs ganham um espaço muito grande na comunicação via web por conta da sua eficiente maneira de comunicar utilizando animação de imagens.

A possibilidade de se criar um GIF com poucos comandos na palma da mão é algo muito atraente e comum na vida de internautas. Vários sites como Imgur, Imgflip, Gifpal são específicos para criação destes. Há também sites como o Techtudo (http://www.techtudo.com.br/dicas-e-tutoriais/noticia/2016/02/como-criar-um-gif-

animado.html) que disponibilizam o passo a passo e explicações básicas para a criação dos GIFs.

Já a função educacional dos GIFs baseia-se no fato de as imagens desempenharem importante papel pedagógico no processo de ensino-aprendizagem dos conceitos científicos das mais diversas ordens (ROCHA et al., 2011). Principalmente pelo alto poder de síntese que possuem e por circular curtos trechos de conteúdo midiático/comunicativo, possibilitando serem utilizados como forma de construção de conceitos científicos, por exemplo. Os alunos cada vez mais conectados demandam estratégias e recursos que os atraem e ao mesmo tempo ensinam algum conceito. Neves (2012) aponta que, é visível cada vez mais cedo, a familiaridade, a curiosidade e o fascínio que as novas tecnologias vem exercendo sobre as crianças.

Percebendo a proposta de integração de novas tecnologias na escola, como estratégia didática, em resposta ás exigências da atual sociedade, faz todo sentido valorizá-la pelos professores com intuito de melhorar o desempenho dos alunos, motivando-os para uma aprendizagem significativa (p.3).

Ainda segundo o autor, utilizar um recurso midiático-pedagógico em contexto escolar abre possibilidades para o professor, para que ele desenvolva novas metodologias, recursos e estratégias interessantes a fim, de realizar atividades que motivem e instiguem a curiosidade dos alunos, gerando a motivação e interesse nas atividades curriculares, orientando-os posteriormente na procura do seu próprio conhecimento (2012, p. 33). 


\section{METODOLOGIA}

Para preparar o professor em formação para enfrentar esses desafios, o curso de Licenciatura em Ciências Biológicas da Universidade Federal de Lavras oferece aos alunos, dentre outras disciplinas, a disciplina de Metodologia do Ensino de Ciências, cursada no 3o período. A disciplina tem como proposta a elaboração e ministração de uma aula na qual seja utilizado um recurso não tradicional de ensino para ensinar um dos eixos temáticos propostos pelo 30 e 4 을 ciclos (ensino fundamental) presentes nos Parâmetros Curriculares Nacionais- PCN- (BRASIL, 1998), sendo eles: Terra e Universo, Vida e Ambiente, Ser Humano e Saúde e Tecnologia e Sociedade. O eixo escolhido para ser abordado foi Terra e Universo e dentro de tal temática foram trabalhados os movimentos da Terra e suas consequências para o planeta, como por exemplo, as quatro estações, solstício e equinócio, ano bissexto, rotação e translação (Quadro 1). A estratégia pedagógica utilizada foram as imagens animadas (GIFs) aliadas à metodologia investigativa.

Quadro 1: Definição dos principais conceitos trabalhados na microaula.

\begin{tabular}{|c|c|}
\hline Conceito & \begin{tabular}{c} 
Definição \\
\hline Rotação
\end{tabular} \\
\hline Translação & $\begin{array}{c}\text { movimento que a Terra realiza em torno de } \\
\text { seu próprio eixo. }\end{array}$ \\
\hline Solstício & $\begin{array}{c}\text { movimento que a Terra realiza em torno do } \\
\text { Solinação do eixo de rotação e a posição da } \\
\text { Terra em relação ao Sol, a incidência de raios } \\
\text { solares nos hemisférios Norte e Sul é } \\
\text { diferente. Em determinado momento, um } \\
\text { hemisfério estará mais voltado para Sol, e seis } \\
\text { meses depois será o outro hemisfério. }\end{array}$ \\
\hline Equinócio & $\begin{array}{c}\text { Equinócio significa noite igual, onde o Sol no } \\
\text { equador, resulta em 12 horas de luz do dia e } \\
12 \text { horas de escuridão. }\end{array}$ \\
\hline
\end{tabular}

Para complementar o processo de ensino aprendizagem com esta estratégia, os GIFs foram aliados ao método investigativo, que segundo Bell et al. (1986), se resume nas ideias que os alunos possuem e não no conhecimento que não possuem, trazendo para as aulas sua perspectiva sobre o assunto. Dessa maneira, através da utilização do conhecimento prévio do aluno é possível aproximá-lo da prática, estimulando-o a participar ativamente do processo de construção do conhecimento, tornando o processo mais dinâmico e sua aprendizagem mais significativa. 


\section{Planejamento da microaula}

Em um primeiro momento, foram discutidas propostas de estratégias de ensino nãoexpositivas, abordando os temas trazidos no terceiro e quarto ciclos do PCN, correspondente ao ensino fundamental, para que os alunos da disciplina pudessem escolher os seus respectivos temas de trabalho, bem como o modo em que iriam fazê-lo. Após o estudo prévio do PCN e análise dos ciclos, a estratégia escolhida para este trabalho foi a utilização de imagens animadas aliadas ao método investigativo para abordar o tema "Terra e Universo". Houve o planejamento e a construção da estratégia pedagógica. Nesse processo, primeiramente foi discutido o que seria abordado, quais conceitos seriam trabalhados e a maneira como isso seria realizado.

Em um segundo momento, após a definição desses quesitos, realizou-se uma busca pelos GIFs que seriam utilizados. Foram selecionados quatro GIFs: um relógio analógico com ponteiros em movimento (Imagem 1), planeta Terra em rotação (Imagem 2), planeta Terra girando ao redor do sol (Imagem 3) e movimentos responsáveis pelo solstício e equinócio (Imagem 4), todos retirados de sites da internet (Anexo 1).

\section{A apresentação da microaula}

No terceiro momento a microaula (simulação de uma aula) proposta foi apresentada para integrantes do Programa de Iniciação à Docência (PIBID) de Biologia da Universidade Federal de Lavras e para os demais alunos da disciplina.

Inicialmente, foi problematizado o porquê de um dia ter 24 horas e se realmente tem este tempo. A partir disso, foi sendo construído durante a discussão, que o dia não tem exatamente 24 horas e sim 23 horas e 56 minutos, e que o movimento responsável pelo dia e a noite é o de rotação. Com o decorrer da investigação/problematização, as imagens animadas foram projetadas de maneira a suprir o diálogo sobre os conceitos abordados. Vale ressaltar que os conceitos abordados foram construídos de forma coletiva entre alunos e professores sempre comunicando com os GIFs utilizados na apresentação.

Adicionalmente foi problematizada a forma que é estruturada um relógio, sendo este dividido em 12 horas. Durante a conversa, os alunos entenderam que essa divisão é feita de tal maneira, pois são consideradas 12 horas de claro, 10 horas de escuro e 2 horas divididas entre anoitecer e amanhecer. Posteriormente, foi questionado quantos dias tem o ano e o porquê de, 4 em 4 anos, fevereiro ter um dia a mais do que nos demais anos. Com isso foi discutido que o ano tem 365 dias e que de 4 em 4 anos é adicionado um dia a mais para repor aqueles minutos que faltavam para completar 24 horas de um dia, assim os anos que tinham um dia a mais foi chamado de ano bissexto, pois há 366 dias.

Encaminhando para o final da microaula foi abordado o outro movimento realizado pela Terra, que é denominado translação. Foi discutido que este é o movimento onde a Terra gira em torno do Sol e foi problematizada qual a influência deste no planeta. As principais influências citadas foram sobre as estações do ano, além das fases chamadas de solstício e equinócio e como algumas culturas celebram esses fenômenos. 
Após a microaula foi requisitado aos matriculados na disciplina e aos bolsistas do PIBID uma avaliação oral sobre a mesma, a fim de se obter dados para posterior análise sobre a metodologia utilizada. Ademais, a microaula foi gravada e as falas foram transcritas.

As falas avaliativas dos participantes foram transcritas e analisadas na perspectiva da metodologia de pesquisa qualitativa (MINAYO, 1999). Para isso foi utilizada a categorização, derivada da análise de conteúdo, como proposto por Minayo (1999). Essa metodologia busca agrupar os dados obtidos baseando-se na similaridade entre eles, seja de ordem semântica ou gramatical, com objetivo de se compreender melhor o fenômeno estudado. As imagens a seguir são uma tentativa de ilustrar o movimento dos GIFs utilizados durante a microaula, porém, devido ao fato de serem imagens animadas, foram capturados dois momentos do ciclo de cada GIF.

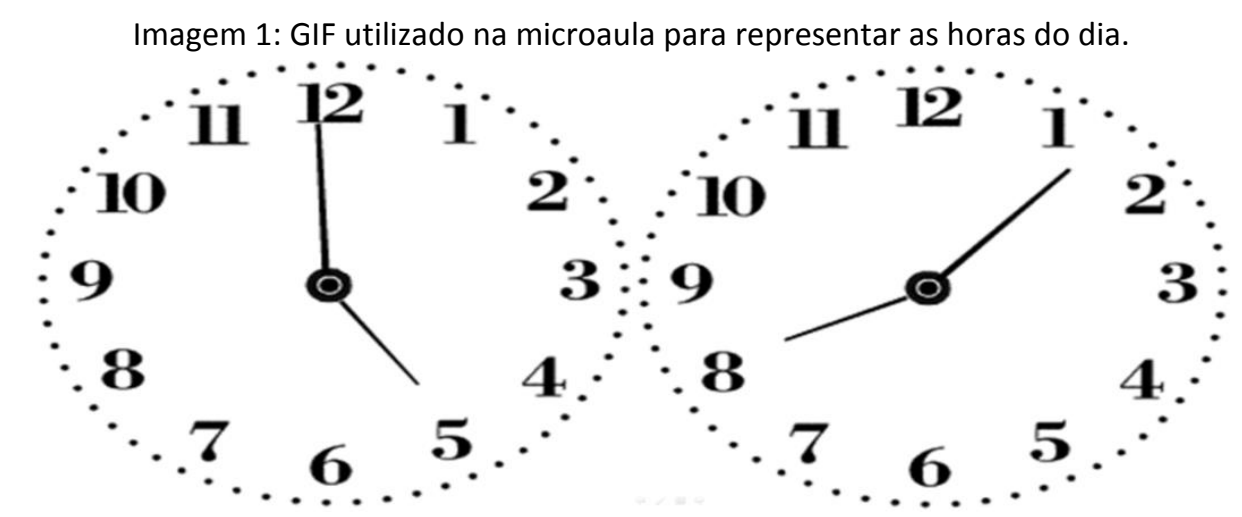

Fonte: http://4.bp.blogspot.com/Clcl9N0J350/VnA1leOP8TI/AAAAAAAAJaw/Vo9xCFuDig0/s1600/-relogio.gif

Imagem 2: GIF utilizado na microaula para representar o movimento de rotação da Terra.

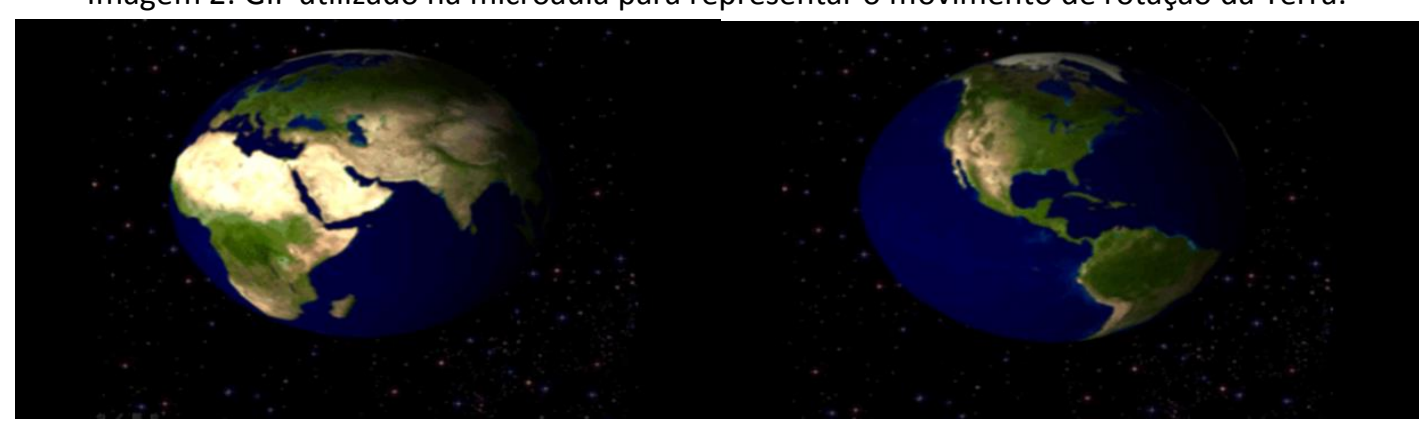

Fonte: http://www.explicatorium.com/images/cfq-7/universo/rotacao-terra.gif 


\section{da Alta Paulista}

Imagem 3: GIF utilizado na microaula para representar o movimento de translação da Terra.

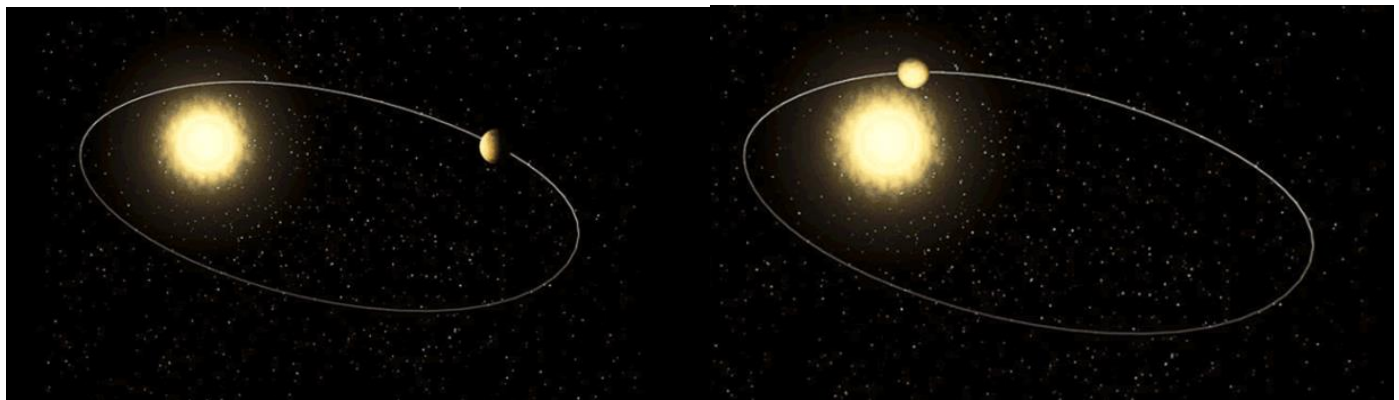

Fonte: http://2.bp.blogspot.com/0Wqn30tDQi4/UiiUk8Fqkbl/AAAAAAAAIHk/zu6BcDG7nE/s1600/02.gif

Imagem 4: GIF utilizado na microaula para representar os movimentos de Solstício e Equinócio.

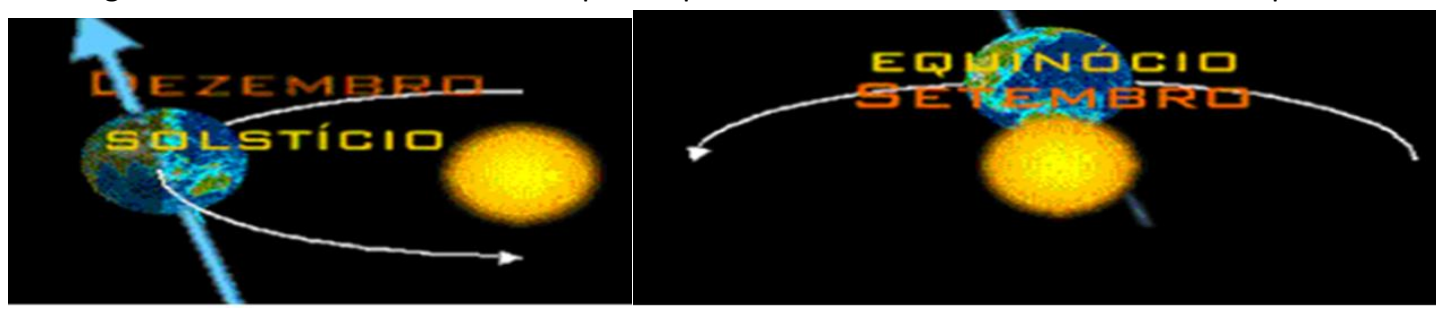

Fonte: http://www.observatorio.ufmg.br/equi02.gif

\section{RESULTADOS E DISCUSSÃO}

A microaula foi gravada em vídeo para posterior transcrição de modo integral (Quadro 2) e análise das falas avaliativas dos alunos da disciplina de Metodologia em Ciências e integrantes do PIBID Biologia. Após serem transcritas, as falas foram nomeadas como PX, onde $\mathrm{P}$ significa "participante" e $\mathrm{X}$, o número que identifica cada um. Em seguida, estas foram agrupadas em categorias como demonstradas nos quadros 3 e 4 .

Quadro 2: Respostas obtidas através da avaliação

P1 - "O que eu achei massa, assim, foi a ideia, assim né. Vocês explicaram usando só as imagens mesmo, não tem tópicos nem nada assim pra lembrar e tal, achei massa."

P2 - "Queria dizer que você prende a atenção assim, dá pra ficar prestando atenção."

P3 - "Eu gostei porque, eu acho interessante mostrar as imagens assim em forma de GIF porque você consegue acompanhar o que acontece, e dai além de você explicar dá pra ver o que acontece, se sua imaginação está de acordo com o que é de verdade."

P4 - "Eu acho que pra uma aula de ciências, de biologia, que seria interessante, mais uma sugestão talvez, acrescentar alguns aspectos biológicos, a interferência das estações, a senescência de folhas... não que seja o objetivo principal trabalhar isso, mas dá pra abordar fácil, é um tema rico pra ser explorado."

P5 - "Ah, eu queria apontar que o seu bom humor, a sua interação com as pessoas, gostei bastante, e também essa parte dessas imagens em movimento, que às vezes também só a imagem não prende tanto a atenção do aluno como se for um GIF, entendeu?! GIF já deixa a coisa mais interativa, sabe?! Mais bonita de se ver." 
P6 - "Eu achei que ficou bem bacana, porque tipo, não sei, quando eu estava no ensino médio quando a professora ia explicar isso ela explicava com um lápis, e quando era inclinação, as vezes ela não conseguia girar assim aí ela acabava girando assim, pra você ver como é, e com esse simples desenho aí, esse GIF, a gente consegue entender perfeitamente a questão da rotação, da translação, e encaixa perfeitamente na explicação que vocês deram e a questão do humor, eu que fiz cursinho e o João também, sabe que deixa a aula bem mais interessante. Parabéns."

P7 - "Vou falar, mas eu fui contemplado, por isso eu vou falar. É... além da interatividade assim, eu queria parabenizar a dupla porque vocês estavam bem coesos. Se completavam às vezes, e isso foi legal de ver. Mas isso do solstício e equinócio que é muito legal e um pouco complicado de entender, e tem a problemática do tempo que é só 20 minutos pra vocês apresentarem, mas desenvolver isso em uma aula com esses recursos e o modo como vocês estavam tratando, ao meu ver, acredito que daria certo."

P8 - "Queria ressaltar o que ele falou, além da interatividade também, é... não sei vocês, mas isso de solstício e equinócio eu vi em geografia, e é a questão assim, naquela parte das estações eu achei muito interessante comentar o porquê das estações, claro também que não tenha sido o foco, mas explicar mais as estações, achei que ficou um pouco vago as estações apenas. E o GIF foi sensacional."

A seguir as falas são apresentadas em suas respectivas categorias:

Quadro 3: Categorias identificadas a partir das falas dos oito participantes.

\begin{tabular}{|c|l|}
\hline \multicolumn{1}{|c|}{ Categoria } & \multicolumn{1}{c|}{ Descrição } \\
\hline Importância da utilização do GIF & $\begin{array}{l}\text { Falas que fazem referência à utilização do GIF } \\
\text { como um potencial recurso pedagógico. }\end{array}$ \\
\hline Prática docente & $\begin{array}{l}\text { Falas que mencionam o desempenho dos } \\
\text { licenciandos que ministraram a microaula. }\end{array}$ \\
\hline Compreensão do tema trabalhado & $\begin{array}{l}\text { Compreensão do tema trabalhado a partir do } \\
\text { recurso utilizado. }\end{array}$ \\
\hline
\end{tabular}




\section{da Alta Paulista}

Quadro 4: Frequência das falas dos oito participantes.

\begin{tabular}{|c|c|c|}
\hline Categoria & Frequência & Participantes \\
\hline Importância da utilização do GIF & 6 & P1, P3, P5, P6, P7 e P8. \\
\hline Prática docente & 5 & P2, P5, P6, P7 e P8 \\
\hline Compreensão do tema trabalhado & 4 & P3, P5, P6 e P8 \\
\hline
\end{tabular}

Na primeira categoria, os alunos apontam a utilização do GIF como um potencial recurso pedagógico. Nas falas aparecem impressões positivas acerca da utilização desse recurso no processo pedagógico, dialogando com a perspectiva de Gibin e Ferreira (2013), que apontam o uso de imagem (no caso deste trabalho uma sequência animada de imagens - GIF), como um elemento mobilizador e motivador entre os estudantes. Estes autores ainda destacam que as imagens podem desempenhar uma importante função no processo de construção de conceitos científicos.

Trovo (2008) afirma que, diante de imagens estáticas ou em movimento, quase que no mesmo momento, tendemos a sermos críticos sobre o que vemos (se estamos capacitados para tal ação) ou simplesmente esquecemos o que acabamos de visualizar, pois não possuímos os argumentos necessários o qual deveriam ter sido adquiridos ao longo de nossa existência sobre o assunto em questão.

Contudo, vale destacar que a utilização desse recurso deve estar aliada a uma prática pedagógica contextualizadora que crie um diálogo entre o objeto de estudo e a imagem utilizada, tendo em vista que o recurso não é auto-explicativo (GIBIN e FERREIRA, 2013).

Imagens animadas utilizadas como recurso pedagógico e de forma contextualizada devem ser inseridas no processo de formação inicial. Esse processo docente contextualizado auxilia os professores em formação a aproximar a realidade de seus futuros alunos. Mello (2001), diz em seu trabalho que é indispensável em seu processo de formação que os conhecimentos específicos sejam contextualizados, podendo ser mediados por diferentes recursos pedagógicos. $\mathrm{O}$ autor ainda trás que dessa maneira se promove uma permanente construção desses conhecimentos e suas aplicações. Na experiência aqui descrita através das falas, foi possível perceber uma grande aceitação deste recurso, o que nos permite inferir que ele pode ser eficaz no processo de ensino-aprendizagem.

$\mathrm{Na}$ segunda categoria, os participantes da atividade ressaltaram a afinidade dos licenciandos com o tema da microaula, bem como a interação professor-aluno, permitindo-nos perceber a importância dos professores terem domínio do assunto/conceito a ser abordado e também a maneira como o conhecimento é construído com os alunos, apontando para um permanente e contínuo processo de formação profissional. 
De acordo com Nóvoa (1992) estar em formação implica um investimento pessoal, um trabalho livre e criativo sobre os percursos e os projetos próprios, com vista à construção de uma identidade, que é também uma identidade profissional. Vale destacar que a identidade docente é construída a partir do diálogo do conteúdo específico de cada área do conhecimento com a prática efetiva da docência, onde o licenciando pode conhecer as possibilidades e limitações da prática docente, e, assim, se propor uma reflexão contínua sobre o seu fazer pedagógico.

Cabe aos professores encontrarem meios para que esse trabalho possa ser repleto de conhecimentos de forma a instigar novas ideias aos alunos (TROVO, 2008). Com essa identidade construída, ou em construção, o professor tem uma motivação maior e, de certo modo, uma facilidade para abordar os conceitos propostos por sua área de atuação e construir os mesmos com os alunos, demonstrando segurança e convicção sobre a aula.

A terceira categoria se refere à compreensão do tema abordado, onde os estudantes apontaram que o recurso empregado facilitou a apropriação do tema trabalhado, possibilitando aos participantes enxergarem de modo mais claro, o conceito. Os conceitos de rotação e translação, ao serem problematizados a partir dos GIFs, de acordo com as falas analisadas, foram melhor compreendidos. Isso nos permite destacar que o uso de recursos midiáticos, como os GIFs, proporciona uma maior aproximação do conceito e, por conseguinte a sua apropriação, como apontado também por Alves e Borges (2015). Para os autores, o processo pedagógico, auxiliado pela utilização destes recursos, pode tornar-se mais lúdico, enriquecendo a aprendizagem dos alunos, conforme foi possível observar na construção da microaula.

A utilização do recurso midiático e, o domínio do conteúdo a ser trabalhado influencia diretamente em como o professor ministrará sua aula, e com isso, resultará em sua identidade como professor, sendo essa, construída nos anos iniciais de sua formação.

\section{CONSIDERAÇÕES FINAIS}

Após a realização da microaula e da análise das falas dos participantes, foi possível notar que a utilização de imagens animadas, como o GIF, é uma estratégia de grande importância para o ensino de ciências e demais áreas. Isso se deve ao fato de que a animação permite uma compreensão mais clara e objetiva do conteúdo, subsidiando a compreensão dos educandos e esclarecendo possíveis dúvidas em alguns conceitos, geralmente considerados abstratos, como os de solstício e equinócio. Contudo, a contextualização da temática trabalhada pelo professor é de suma importância para a compreensão da mesma, permitindo também um diálogo efetivo do conteúdo trabalhado com o dia a dia do aluno.

Outro ponto a ser considerado é a interação professor- aluno, observado na prática e destacado pelos participantes em suas avaliações, pois uma boa relação entre estes sujeitos do processo de ensino-aprendizagem contribui para um melhor desenvolvimento da aula e consequentemente para o aprendizado dos educandos.

A partir destas colocações, é possível afirmar que utilizar os GIFs, para o ensino de ciências é bastante eficaz na construção do conhecimento trabalhado, uma vez que transcende a 
perspectiva do visual e se mostra efetivo ao incorporar os conceitos trabalhados no repertório dos educandos. Essa pesquisa tem futuras perspectivas em ser aplicada em uma escola, além de ser um instrumento de grande potencial na formação inicial de professores.

\section{REFERÊNCIAS BIBLIOGRÁFICAS}

ALVES, L. H. BORGES, D. C. S. Recursos Audiovisuais como ferramenta didático-metodológica facilitadora no processo de ensino aprendizado em Ciências. Athos \& Ethos, v. 11, p. 93-111, 2015.

BELL, B., WATTS, M. \& WILSON, C. (1986). Children's learning: Interactions between teachers and researchers. School Science Review, 66, pp. 651-657.

BÉVORT, E. BELLONI, M. L. Mídia-Educação: Conceitos, História e Perspectivas. Educ. Soc., Campinas, vol. 30, n. 109, p. 1081-1102, set./dez. 2009.

BRASIL. Ministério de Educação e Cultura. Lei de Diretrizes e Bases - Lei no 9394/96, de 20 de dezembro de 1996. Estabelece as diretrizes e bases da Educação Nacional. Brasília: MEC, 1996.

BRASIL. Conselho Nacional de Educação. Parecer CNE/CES no 776, Orientação para as diretrizes curriculares dos cursos de graduação. 1997c. Disponível em: <http://portal.mec.gov.br/sesu/arquivos/pdf/pareceres/ces0776.pdf> Acesso em 17/02/2017.

BRASIL. Ministério de Educação. Parâmetros Curriculares Nacionais: terceiro e quarto ciclos: Temas Transversais. Secretaria de Ensino Fundamental. Brasília: MEC/SEF, 1998.

CAPES. Descrição do PIBID. 2008. Disponível em: http://www.capes.gov.br/educacao-basica/capespibid/pibid.

DE CASTRO, M. G. B. Uma retrospectiva da formação de professores: histórias e questionamentos. movimentorevista de educação, n. 4, 2016.

DORIGONI, G. M. L., \& SILVA, J. C. D. Mídia e Educação: o uso das novas tecnologias no espaço escolar. Santa Catarina: UNIOESTE, 2-3, 2008.

FANTIN, M. and GIRARDELLO, G. E. P. "Diante do abismo digital: mídia-educação e mediações culturais." Perspectiva 27.1; 69-96, 2010.

FREIRE, P. Pedagogia do Oprimido. Rio de Janeiro, Ed. Paz e Terra, 2015.

GATTI, B. A. (2010). Formação de professores no Brasil: características e problemas. Educação e Sociedade, Campinas, 31(113), 1355-1379.

GIBIN, B. G.; FERREIRA, L. H. Avaliação dos estudantes sobre o uso de imagens como recurso auxiliar no ensino de conceitos químicos. Química Nova na Escola, v. 35, n. 1, p. 19-26, 2013.

KUENZER, A. Z. As políticas de formação: a constituição da identidade do professor sobrante. Educação $e$ sociedade, 20(68), p. 166, 163-183, 1999.

LOPES, A. O. \& Veiga, I. P. A. Aula expositiva: superando o tradicional. Técnicas de ensino: por que não, 2, 35-113, 1995. 
LUPINACCI, L. Eu tenho tanto pra Ihe falar, mas com palavras não sei dizer: GIF animado como recurso expressivo. XXXIX Congresso Brasileiro de Ciências da Comunicação - São Paulo - SP - 05 a 09/09/2016.

GIF Animado e conteúdo espalhável: análise do uso do formato no VMA 2013. XXXVII Congresso Brasileiro de Ciências da Comunicação - Foz do Iguaçu, PR - 2 a 5/9/2014.

DE MELLO, G. N. Formação inicial de professores para a educação básica: uma (re) visão radical. Revista iberoamericana de Educación, n. 25, p. 147-174, 2001.

MIGLIOLI, S. BARROS. M. Novas tecnologias da imagem e da visualidade: GIF animado como videoarte. Revista Sessões do Imaginário n. 29, p. 68-75. 2013.

MINAYO, M. C. S. O desafio da pesquisa social. In: (Org.) Pesquisa Social: Teoria, Método e Criatividade. 14. ed. Ed. Vozes; Petrópolis, 1999.

NEMIROFF, R.; BONNELL, J. (23 de setembro de 2010). «Equinox and the Iron Sun» (em inglês). NASA. Consultado em 17 de fevereiro de 2017.

NEVES, S. R. C. S. R. Abordagem com Técnicas de Imagem Animada: Uma estratégia de motivação e desenvolvimento de competências no 2o ciclo Relatório. 2012. 164f. Relatório de mestrado (Mestrado em Ensino de Educação Visual e Tecnológica no Ensino Básico). Universidade do Algarve- Escola Superior de Educação e Comunicação. Faro, Portugal, 2012. p. 53.

NÓVOA, A. A Formação de professores e profissão docente. In: NÓVOA, A. Os professores e a sua formação. Lisboa: Publicações Don Quixote, 1992. p. 13-33.

NÓVOA, A. Evidentemente - Histórias da educação. Porto: Edições ASA, 2005.

OLIVEIRA, N. M. F. e COUTINHO. F. A. A influência das cores na identificação e interpretação de imagens no ensino de ciências. Encontro nacional de pesquisa em educação em Ciências. Florianópolis 2009.

PENA, R. F. A. "O que é rotação e translação?"; Brasil Escola. Disponível em <http://brasilescola.uol.com.br/o-quee/geografia/o-que-e-rotacao-translacao.htm>. Acesso em 17 de fevereiro de 2017.

PIMENTA, S. G. Formação de professores: saberes da docência e identidade do professor. Revista da Faculdade de Educação, v. 22, n. 2, p. 72-89, 1996.

ROCHA, J. A.; PEREIRA, R. V.; HENRIQUES, C. Imagem como ferramenta de Eficiência Cognitiva para o Ensino de Ciências, 2011. 2012.

SAVIANI, D. Formação de professores: aspectos históricos e teóricos do problema no contexto brasileiro. Revista brasileira de Educação, 14(40), 143, 2009.

SILVA, H., C.; ZIMMERMANN, E.; CARNEIRO, M.H.S.; GASTAL, M.L.; CASSIANO, W.S. Cautela ao usar imagens em aulas de Ciências Ciência E Educação, v. 12, n. 2, p. 219-233, 2006.

SILVA, M. P., \& JUNIOR, A. F. N. Atividades formativas do pibid de biologia da universidade federal de lavras: uma perspectiva crítica de formação inicial de professores. 2014. Trabalho de conclusão de curso Ciências Biológicas Licenciatura Plena, Universidade Federal de Lavras.

SUHR, K. Using Animated GIF Images for Library Instruction. In the Library with the Lead Pipe, 2014. 
TROVO, A. W. As tecnologias no ensino de geografia-"o uso das imagens como interpretação do meio em que vivemos". Paraná: UFPR, 2008.

WAGNER, C. Z. o Espírito do Tempo - Experiências Estéticas. Rev. Cult. e Ext. USP, São Paulo, n. 12, p.21-29, nov. 2014. 